\title{
USING THE ECONOMICAL-MATHEMATICAL MODELLING IN THE CONSTRUCTIVE PREPARATION OF PRODUCTION
}

\author{
Ioan Constantin Dima ${ }^{1}$, Mariana Man ${ }^{2}$, Janusz Grabara ${ }^{3}$ \\ ${ }^{1}$ University "Valahia" of Targoviste, Romania \\ ${ }^{2}$ University of Petrosani, Romania \\ ${ }^{3}$ Czestochowa University of Technology, Poland
}

\begin{abstract}
The constructive preparation of industrial production aims at determining the physical and chemical properties, the external appearance and other elements regarding quality, which shall allow the product in question to meet the requirements of national economy in the fields of usage and consumer requirements. The starting point lies in the knowledge of the pursued goal, i.e. the product type and the requirements it must meet in terms of consumers and national economy. The knowledge of the destination of the new product and the usage thereof determines the technical solutions to be adopted.
\end{abstract}

Keywords: the constructive preparation, usage value, exchange value, esteem value, market value, customer value, the integration of production, production scheduling

\section{Introduction}

The constructive design activity is influenced by several factors, such as: operating conditions; the means of accomplishment of the structural conception of the construction of the new product; the means of material accomplishment of the product's construction; savings in manufacturing and operation.

The establishment of the optimal solution implies both the knowledge of the system of connections between factors and the determination of those factors with a high influence on the given solution. Thus, the functions of the product, the constructive solution, the shape of parts and materials, the technologies of execution and the level of costs lie at the centre of the system of connections between the factors finally determining the optimal solution.

\section{The constructive preparation}

According to the methodology, the conception of new products includes:

- the elaboration of the design topic and the feasibility study, which include the initial basic data, depending on which the technical project and the execution drawings shall be made;

- the elaboration of the technical project includes: the main calculation elements of the product, the global and sectional drawing, the tender book; 
- the elaboration of execution drawings completes the constructive preparation activity of the new product and is elaborated on the basis of the technical project, showing in detail all the constructive elements for each part, benchmark, half-finished product or sub-assembly of the new product. The technology for the manufacture and performance of the product within the company's sections shall be elaborated on basis thereof. Technical drawings also include technical service and maintenance notes for various parts or assemblies.

The method of value analysis referring to the product is used for the successful constructive preparation of the product, as the product only carries usage value. For the application of this method, the functional characteristics of the product are more important than the structural ones, as focus is given to the analysis of product functions.

Product functions may be grouped into: usage functions (objective, directly measurable and noticed by the user); appreciation functions (subjective, hardly measurable, directly noticed by the user); constructive connection functions (objective, measurable, only perceived by the user in negative display).

Useful functions are only those contributing to the accomplishment of the usage value of the product in question.

According to the opinions in the specialised literature, the components of the value of a product are the following: the wishes of customers who possess financial resources, but who are not satisfied and who represent what we call market; the use of the product for such customers, i.e. it has to meet certain market requirements; the product variety or the difficulty to obtain it; the total cost for the customer, which the latter desires to be as low as possible; the customers' possibilities to choose, i.e. the existence of competition.

The interaction of these elements results in the definition of the value of an industrial product, as determined by the special relationship between utility and cost, which depends both on the customer's wishes and his/her resources, in a certain given situation.

Human need has defined value in several ways, as follows: usage value, exchange value, esteem value, market value, customer value.

In terms of value analysis the aspects of economic value may be classified into: usage value, estimation value, exchange value, market value.

The implementation of this method requires the organisation of specialised work groups. In setting up such groups, the professional knowledge of members must be assessed, so that the balanced combination thereof should result in meeting product requirements. As a principle, these groups are on average made up of five people, with a minimum number of three and a maximum of seven. The set up group shall establish its own work plan.

The value analysis follows the general model of scientific methods, i.e. problem solving and innovation application in a workgroup characteristic to group dynamics and implies undergoing the following phases: 
- the initial phase of value analysis, when the group elaborates the information sheet, solving the following issues: the identification of the project (work); the definition of the study field; the determination of the product quantity and life; marketing conditions; revision of cost-related data; the collection of additional required information; the use of unsolicited information; the presentation of the most important facts;

- the analytical phase, when answers shall be given to the following questions (Tab. 1): What does the product do?; How much does the product cost?; How much should the product cost?

- the creation phase, when solutions for the following issues are tried out: How can the product be improved?; Can innovations be made?; Is there a possible simplification of the issue?;

- the evaluation phase considers the measurement of the results of the creative activity, solving the following issues: the possible application of the Combinex method; choosing the manufacturing method; comparing value analysis options;

- checking the solutions obtained after the evaluation, that is: What does it bring to us?; How much does it cost us?; Which are the risks?;

- any recommendations pursuant to the check of the chosen solutions, materialised in: proposing a course of action; setting up the implementation plan;

- the implementation of the adopted solutions takes into account: the factors determining acceptance; acceptance conditions; the implementation mechanism.

Table 1

The definition and measurement of functions

\begin{tabular}{|c|c|c|c|c|c|c|c|c|c|}
\hline \multirow{2}{*}{$\begin{array}{c}\text { The system, assembly, } \\
\text { benchmark or process }\end{array}$} & \multicolumn{3}{|c|}{$\begin{array}{c}\text { What functions does it } \\
\text { have? }\end{array}$} & \multicolumn{5}{c|}{ Degrees } & Calculated \\
cost
\end{tabular}

According to the analysis of this plan, we conclude that the essence of value analysis consists in the question: can the function of a product or an element thereof be accomplished by reducing costs?

The answer to this question is related to the logical process in value analysis, which basically consists of: the analysis of the way in which the product meets certain requirements or necessities and, hence, the identification of the product functions; establishing the costs for the parties in the material structure of the product, involved in obtaining the product functions; presenting, for each function, the elements in the material structure serving to obtain this function and the elements 
in direct contact with the outer environment; the analysis of the conception function, independent from the company's environment, but determined by the structure of the internal elements of the product; the analysis of the functions of each component benchmark of the product for establishing the constructive and technological solutions resulting in the accomplishment of these functions with minimal costs.

Value analysis must be present both in product conception and execution phases, after obtaining the first copies, and also for the entire existence of the product. Its purpose is to introduce, especially at the level of product conception, the methods, knowledge and attitudes able to orient companies towards highly economical technical solutions.

In order to reach the goals pursued by applying value analysis, we recommend a close consideration of the following requirements: avoiding generalities, collecting all the information available on manufacturing costs, avoiding use of uncertain information sources, giving up the old conception, improving it or elaborating a new one, using specialists, calculating all dimensional tolerances, using specialised technological procedures, using guidelines, rules and standards etc.

The implementation of the value analysis plan is usually carried out in seven phases, as follows: the orientation phase, the information phase, the reflection and creation phase, the analysis phase, the work plan elaboration phase, the phase of the proper performance of the programme, the phase of elaboration of the results and conclusions chart.

For simplification, we shall consider a product accomplishing two functions: $F_{1}, F_{2} \ldots$ and made up of three benchmarks: $r_{1}, r_{2} \ldots r_{3}$. In the first phase, by asking the question "Which are the tasks of this product in its current form?", we determine the basic functions of the product, i.e. $F_{1}$ and $F_{2}$. In the second phase, we examine the components of the product, i.e. benchmarks $r_{1}, r_{2}$ and $r_{3}$, asking the same question for each of them as for the product, with the resulting functions $F_{11}$ and $F_{12}$ for the benchmark $r_{1} ; F_{21}$ and $F_{22}$ for the benchmark $r_{2}$ and $F_{31}$ for the benchmark $r_{3}$. Thereafter, second degree functions $\left(F_{11}, \ldots, F_{31}\right)$ are classified according to the main functions, which is why the following question is asked for each second-degree function: What do these functions fulfil? The answers to this question must indicate one of the main functions. We get a gross chart of functions, which, by similar methods, may be detailed up to the required level (Fig. 1).

In order to accomplish each product, expenses by functions and the share of functions should be established. The expenses for the accomplishment of a function are determined on the accomplish basis of the level of expenses for the accomplishment of the product and the identification of the holder of each product function. The function share shows the contribution of a partial function or a low-order function to the accomplishment of a global function, respectively an immediately higher order function. Based on this share coefficient, we get a final approximate allocation of expenses for each separate function. 


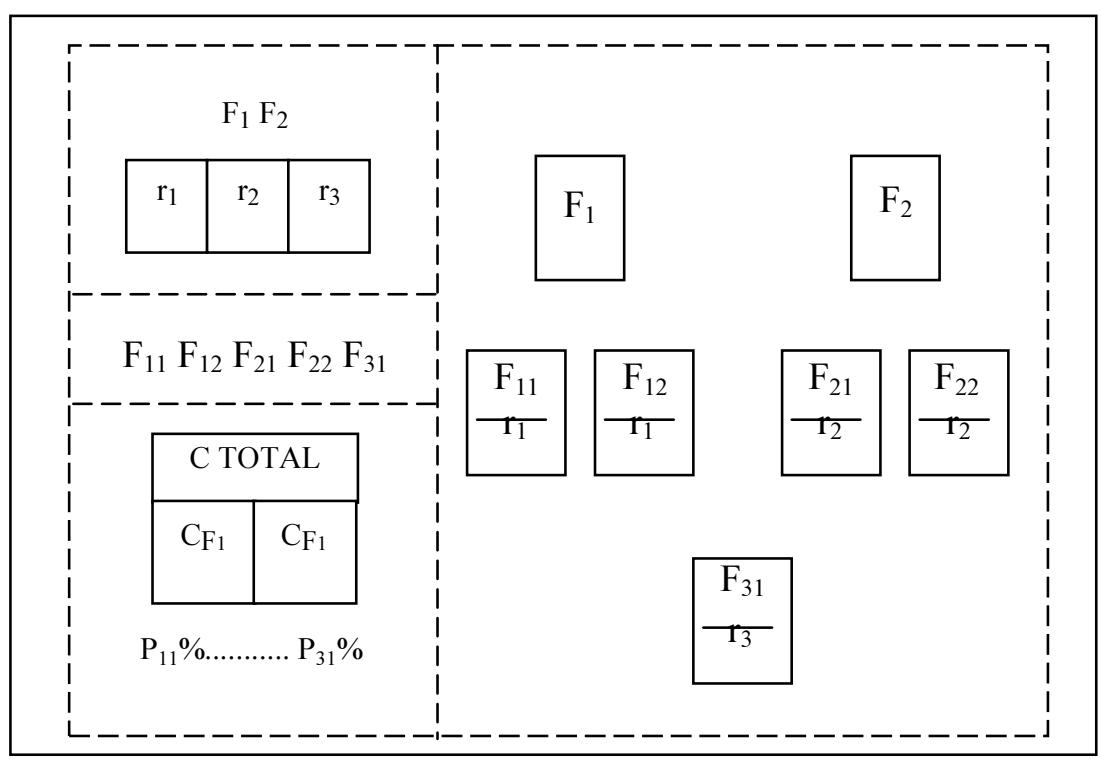

Fig. 1. The gross scheme of product functions

\section{The integration of production}

The deepening of social division of work in industry results in the creation of companies specialized in the manufacturing of benchmarks, sub-assemblies, assemblies, products or the performance of various technological phases and steps. For this reason, a very important issue for each industrial company consists in the analysis of the possibility to execute, under profitability conditions, several components of the finished products, or operations, phases and technological steps, in other specialised companies, on the basis of cooperation relationships.

Cooperation represents the system of connections established on the production line between the companies participating in the manufacture of a complex product, each of them being specialised in the manufacture of certain parts of the product or in the performance of certain manufacture phases. The coordination of the activity thereof is the responsibility of a single company, which has the purpose to deliver the finished product on time and which is in charge of the established technical and quality level.

These actions result in: the determination of the profile and degree of specialisation in final products of the coordinating company; the extension in the specialisation of cooperating companies in the performance of certain benchmarks or subassemblies; the creation of companies specialised in the performance of certain operations or technological phases; the creation of advantageous conditions for the diversification of industrial production; the reduction of the manufacture cycle in products accomplished through cooperation etc. 
The determination of the component benchmarks of the end product of the operations and technological phases to be performed at an internal level or through cooperation is based on: the volume and structure of the programmed manufacturing task, the extension of production capacities and internal or cooperation manufacturing expenses related to the components or technological phases required for obtaining the products.

This activity is rather laborious and develops in several phases, in order to establish the option to perform the final product at an internal level or through cooperation with companies in the country and abroad, as follows:

- the determination of the structure of products and the production volume by

benchmarks and benchmarks-operations, which the option refers to, because,

for the manufacturing of each product, several benchmarks are needed which may be grouped into: benchmarks which cannot be made by cooperation, which is why they must be made entirely within the company; benchmarks which may be made through cooperation, although they could be made internally in all technological operations, and benchmarks which may be obtained internally or through cooperation, only in certain technological operations;

- the determination of the production capacity by production chains able to perform the benchmarks or benchmarks-operations the option refers to, between internal fabrication and cooperation, according to the following formula:

$$
C_{d}=C_{T}-C_{n c}-C_{r i}
$$

where:

$C_{d}$ - represents the production capacity available for the performance of benchmarks or operations, which can be made either internally or through cooperation;

$C_{T}$ - the total production capacity;

$C_{n c}$ - the production capacity of the benchmarks the option does not refer to;

$C_{r i}$ - the production capacity of the benchmarks and operations which can only be made internally.

- the determination of the unitary production expenses required for obtaining benchmarks or the performance of benchmark operations in the two alternatives, internally or through cooperation, which implies the inclusion of the expenses generated by each alternative, depending and specific thereto;

- the elaboration of the mathematical model for choosing the manufacture alternative, resorting to mathematics. Supposing that one may accomplish products which require $\mathrm{m}$ types of benchmarks, of which the first $\mathrm{k}$ may be done in all operations by cooperation, and the following only in certain technological operations and that each technological operation is made in a single production chain, a matrix may be elaborated (Tab. 2) which results in the following linear programming model: 


$$
\max (\min )\left[\sum_{j=1}^{k}\left(C_{o p j}^{I} \cdot X_{j}^{I}+C_{o p j}^{C} \cdot X_{j}^{C}\right)+\sum_{i=1}^{m} \sum_{j=k+1}^{m}\left(C_{o p i j}^{I} \cdot X_{i j}^{I}+C_{o p i j}^{C} \cdot X_{i j}^{C}\right)\right]
$$

with the restrictions:

- not to exceed the programmed quantity;

$$
\begin{gathered}
X_{j}^{I}+X_{j}^{C}=Q_{j} \quad(j=\overline{1, k}) \\
X_{i j}^{I}+X_{i j}^{C}=Q_{j} \quad(i=\overline{1, m} ; j=\overline{k+1, n})
\end{gathered}
$$

- not to exceed the production capacity of the production chain:

$$
\sum_{j=1}^{k} t_{i j} \cdot X_{j}^{I}+\sum_{j=k+1}^{n} t_{i j} \cdot X_{i j}^{I} \leq T_{d i} \quad(i=\overline{1, m})
$$

- the non-negativity restriction:

$$
X_{j}^{I}, X_{j}^{C}, X_{i j}^{I}, X_{i j}^{C} \geq 0 \quad(i=\overline{1, m} ; j=\overline{1, n})
$$

where:

$X_{j}^{I}, X_{j}^{C} \quad$ - represents the quantity of the $R_{j}$ benchmark to be processed in all operations in the coordinating, respectively collaborating company;

$X_{i j}^{I}, X_{i j}^{C} \quad$ - the quantity of the $R_{j}$ benchmark to be processed in the $O_{i}$ operation at an internal level, respectively in the collaborating company;

$t_{i j} \quad$ - the time required for processing the $O_{i}$ operation of an $R_{j}$ benchmark in the coordinating company;

$T_{d i} \quad$ - the time available in the $i$ production chain remaining after the subtraction of the time required for processing benchmarks which do not present the possibility of cooperation;

$C_{o p j}^{I}, C_{o p j}^{C}$ - the value of the optimisation criterion related to the $R_{j}$; benchmark, in the case of internal manufacture, respectively by cooperation;

$C_{o p i j}^{I}, C_{o p i j}^{C}$ - the value of the optimisation criterion related to the $O_{i}$; operation at the $R_{j}$ benchmark, in the case of internal manufacture, respectively by cooperation.

The integration and cooperation activity lies within the attributions of a department dealing with specialisation and cooperation issues, with the following tasks: determining the required amount of benchmarks for the programmed production, according to the regulations in force; determining the product benchmarks to be accomplished by one's own efforts and the benchmarks obtained by cooperation; determining delivery charts with the supplier companies, for the contracted bench- 
marks; providing the performing company with technical documentation and the other elements provided for in the tender book that lied at the basis of the contract etc.

Table 2

The optimisation matrix for the internal-cooperation option

\begin{tabular}{|c|c|c|c|c|c|c|c|c|c|c|}
\hline \multirow{2}{*}{ Benchmarks (i) } & \multicolumn{2}{|c|}{ O1 } & \multicolumn{2}{|c|}{$\mathrm{O} 2$} & \multirow[t]{2}{*}{... } & \multicolumn{2}{|c|}{ Om } & \multicolumn{2}{|c|}{$\begin{array}{l}\text { The value } \\
\text { of the criterion } \\
\text { to be optimised }\end{array}$} & \multirow[t]{2}{*}{ Quantity } \\
\hline & $\mathrm{Fi}$ & $\mathrm{C}$ & $\mathrm{Fi}$ & $\mathrm{C}$ & & $\mathrm{Fi}$ & $\mathrm{C}$ & $\mathrm{Fi}$ & $\mathrm{C}$ & \\
\hline \multicolumn{11}{|l|}{$\mathrm{R}_{\mathrm{i}}$} \\
\hline \multicolumn{11}{|l|}{$\cdot$} \\
\hline \multicolumn{11}{|l|}{$\mathrm{R}_{\mathrm{n}}$} \\
\hline $\begin{array}{l}\text { Available times of the } \\
\text { production chain }\end{array}$ & & & & & & & & & & \\
\hline
\end{tabular}

Legend: $\mathrm{Fi}$ - internal manufacture.

$$
\text { C - cooperation. }
$$

In order to characterize the specialisation-cooperation activity, one must calculate the degree of integration of the production of a company, which expresses the direct ratio it holds in the manufacture of a product, through internal fabrication. A company is totally integrated when it does all the components and technological sheets required for obtaining a finished product.

The extension of cooperation relations with other companies, for the accomplishment of benchmarks or benchmark operations results in the decrease of the degree of integration of the manufacture of the company in question and, implicitly, in the increase of the degree of specialisation of the beneficiary company.

The degree of integration of the production of an industrial company in the manufacture of a product is generally calculated on a percentage basis, as follows:

$$
G_{r i f}=\frac{\sum_{j=1}^{k} R_{j}^{I} \cdot C_{p j}^{I}}{\sum_{j=1}^{k} R_{j}^{I} \cdot C_{p j}^{I}+\sum_{k=1}^{n} R_{k}^{C} \cdot C_{p k}^{C}} \cdot 100
$$

where:

$G_{r i f} \quad$ - represents the degree of integration in the manufacture of a product;

$R_{j}^{I}, R_{k}^{C}$ - the total quantity of the benchmarks or benchmark operations to be processed internally, respectively through cooperation;

$C_{p j}^{I}, C_{p k}^{C}$ - the cost of internally processing a benchmark or benchmark-operation, respectively through cooperation. 
The calculation of the integration degree excludes product components obtained on the market. If $G_{p r i}=100$, the company is fully integrated; otherwise, it is not.

A company may choose between fully manufacturing benchmarks or obtaining them through cooperation, which is why it establishes an optimal level of the degree of integration, meeting the following optimisation criteria: minimisation of production expenses, maximisation of total profit, maximisation of the production amount etc.

The use of each criterion results in a certain variant of the degree of integration, from which the optimal one shall be chosen. To this purpose, we recommend the use of several criteria: the degree of usage of production capacity, the value of obtained profit, the increase in production expenses, the duration of the manufacture cycle.

Table 3

The matrix of multi-criterial decision

\begin{tabular}{|c|c|c|c|c|}
\hline Variants & $\mathrm{C} 1$ & $\mathrm{C} 2$ & $\ldots$ & $\mathrm{Cn}$ \\
\hline $\begin{array}{c}\text { V1 } \\
\cdot \\
\cdot \\
\text { Vn }\end{array}$ & & & & \\
\hline
\end{tabular}

We refer, hence, to making a multi-criterial decision, which may be represented as a matrix (Tab. 3).

\section{Production scheduling}

In order to establish the succession of operations by machines and tools and the optimal charging therein, one may successfully use the operational calculation method, as production scheduling aims at minimising manufacture expenses.

Hence, the goal function is the expense function, which must meet several type of criteria: the logical succession of operation, the non-interference conditions of operations, the particularities of the time usage of production capacities etc.

The models which may be used are:

- determinist, with a discrete and continuous structure:

$$
\begin{aligned}
Z_{0}= & \sum_{t=0}^{p-1} f[v(t)]+c_{s} \sum_{t=0}^{p-1}[P(t)-C(t)+S(o)]+ \\
& +c_{p} \sum_{t=0}^{p-1}[C(t)-P(t)+S(o)]+p_{n} \cdot I_{0}
\end{aligned}
$$


and:

$$
\begin{aligned}
Z_{0}^{\prime}= & \left\{\int_{0}^{t} f[v(t)] d t+c_{s} \int_{a}^{b}[P(t)-C(t)+S(o)] d t+\right. \\
& \left.+c_{p} \int_{a}^{d}[C(t)-P(t)+S(o)] d t+p_{n} \cdot I_{0}\right\}
\end{aligned}
$$

- probabilistic, with a discrete and continuous structure:

$$
\begin{aligned}
Z_{0}= & \sum_{t=0}^{p-1} f[v(t)] P[v(t)]+c_{s} \sum_{t=0}^{p-1}[P(t)-C(t)+S(o)] \cdot P[C(t)]+ \\
& +c_{p} \sum_{t=0}^{p-1}[C(t)-P(t)-S(o)] \cdot p[C(t)]+p_{n} \cdot p_{0} \cdot I_{0}
\end{aligned}
$$

and:

$$
\begin{aligned}
Z_{0}^{\prime}=\int_{0}^{T} f[v(t)] P[v(t)] d[v(t)]+c_{s} \int_{a}^{b}[P(t)-C(t)+S(o)] P[C(t)] d C(t)+ \\
+c_{p} \int_{a}^{d}[C(t)-P(t)-S(o)] P[C(t)] d C(T)+\left[p_{n} \cdot p_{0} \cdot I_{0}\right]
\end{aligned}
$$

where:

$f(v) \quad$ - represents the production function;

$P(t)$ - resources;

$C(t)$ - demand;

$S(o) \quad$ - the initial stock;

$c_{s} \quad$ - the storage cost;

$c_{p} \quad$ - the shortage cost;

$p[v(t)]$ - probability;

$p \quad$ - the number of calculation steps;

$P[C(t)]$ ssi $P_{0}$ - the probability of demand, respectively of performance of the investment;

$a, b, c, d, T$ - limits in the variation of shortage stock and production function.

Based on these models for scheduling the production of an industrial company, considered as an industrial system with a discrete structure, the goal function is:

$$
\min Z_{0}=\min \left[\sum_{i=1}^{a_{1}} \sum_{j=1}^{a_{2}} p_{i j} \cdot X_{i j}+p_{n} \cdot I_{0}\right]
$$


with the following restrictions:

$$
\begin{gathered}
t_{j}-t_{i} \geq t_{i j} \text { for the succession of works } \\
t_{j}-t_{i} \geq t_{i j} \cdot V\left(t_{i}^{C}-T_{j}^{C}\right) \geq t_{i} \text { for non-interference of operations } \\
t_{j}-t_{i}^{c} \geq t_{i}-T_{c j} \text { for the work period } \\
T_{c} \geq t_{i}^{c}+t_{i}-t_{j}^{c} \text { for the duration of the production cycle } \\
x_{j}>0 ; x_{i}>0 \text { for non-negativity }
\end{gathered}
$$

where:

$t_{i}, t_{j}$ - represents the duration of performance of the $i$, respectively $j$ operation;

$T_{c}$ - the duration of the manufacture cycle.

Solving the model results in establishing the size of $X_{i j}$, which must meet the system of restrictions accompanying the goal function.

\section{Conclusions}

The entire constructive preparation activity must envisage the fulfilment of several requirements, such as: the extension of the assortment of products and the continuous improvement in the quality thereof; the compulsory use of internal guidelines and existing standard for designing products; pursuing the cost reduction of the new product in comparison to similar products; the improvement of operating indicators by extending the usage duration; ensuring a concordance between the technical and economic indicators of the new products and the requirements of market economy; the conception of products ensuring the fulfilment of NTS as they are performed. By fulfilling these requirements, one may ensure the diversification of production and the increase in the degree of competitiveness of products at the world level.

\section{References}

[1] Dima I.C., Marcincin I.N., Grabara J., Pachura P., Kot S., Man M., Operational Management Systems of the Production Achieved in Flexible Manufacturing Cells, Techinical University of Kosice, Presov 2011.

[2] Dima I.C., Nowicka-Skowron M., Grabara J., Equipment Replacement Decisions Models with the Context of Flexible Manufacturing Cells in Flexible Manufacturing Cells in Industrial Engineering: Concepts, Methodologies, Tools, and Applications (3 Volumes), IGI Global, 2011.

[3] Dima I.C., Vilkul I., The Economy of the Contemporary Firm, Editura AGIR, Bucureşti 2006. 
[4] Juran J.M., Gryna F.M. Jr., Quality Planning and Analysis from Product Development through Usage ( $3^{\text {rd }}$ ed.), McGraw Hill, New York 2003.

[5] Kot S., Ślusarczyk B., Process simulation in supply chain using logware software, Annales Universitas. Apulensis Ser. Oeconomica 2009, 2, 11.

[6] Maynard H.B., Industrial Engineering Handbook (5th ed.), McGraw Hill, New York 2001.

[7] Modrak V., Pandian R.S., Operations Management Research and Cellular Manufacturing Systems, Hersey: IGI Global, 2012.

[8] Stewart G., Successful Sales Management, England: Pitman Publishing, London 1993. 